\title{
Would early removal of indwelling catheter effectively prevent urinary retention after hip fracture surgery in elderly patients?
}

\author{
Dae-Kyung Kwak', Chul-Young Oh ${ }^{1,2}$, Jeong-Seop Lim ${ }^{1}$, Hyung-Min Lee ${ }^{1}$ and Je-Hyun Yoo ${ }^{1 *}$ (D)
}

\begin{abstract}
Background: This study aimed to investigate the incidence and risk factors of postoperative urinary retention (POUR) among elderly patients who underwent hip fracture surgery and to evaluate the effect of indwelling catheterization on the occurrence of POUR.

Materials and methods: From January 2012 to January 2015, consecutive patients aged over 70 years who underwent hip fracture surgery were enrolled in this study. All patients underwent indwelling catheterization due to voiding difficulty upon admission. Demographic data, perioperative variables, and postoperative duration of patient-controlled analgesia and indwelling catheterization, postoperative complications, and mortality were collected. The incidence of POUR was investigated, and the risk factors related to POUR were analyzed using a logistic regression analysis. The cutoff value for the timing of catheter removal was determined using receiver operating characteristic $(\mathrm{ROC})$ curve analysis.

Results: POUR developed in 68 patients (31.8\%) of the 214 patients. Of these, 24 (35.3\%) were male. The indwelling catheter was left in place for an average of 3.4 days (range, 0-7 days) postoperatively. A significant difference was noted in gender and duration of indwelling catheterization between patients with POUR and without. The cutoff value for the timing of catheter removal as determined by ROC curve analysis was 3.5 postoperative day with $51.4 \%$ sensitivity and $71.5 \%$ specificity. Multiple logistic regression revealed that the duration of the indwelling catheter [odds ratios $(\mathrm{OR}), 0.31 ; p=0.016)$ ] and male gender $(\mathrm{OR}, 2.22 ; p=0.014)$ were independent risk factors related to the occurrence of POUR.

Conclusions: The significant risk factors of POUR among elderly patients undergoing hip fracture surgery were early indwelling catheter removal and male gender. Therefore, early removal of indwelling catheter in elderly patients following hip fracture surgery may increase the risk of POUR, especially in male patients.
\end{abstract}

Keywords: Elderly patients, Hip fracture surgery, Postoperative urinary retention, Indwelling catheterization

\section{Introduction}

Postoperative urinary retention (POUR) is a well-known complication of various surgical procedures, especially in elderly patients, with a reported prevalence of $5-70 \%[1,2]$. Urinary retention is a relatively common complication among patients with hip fracture, and its incidence may reach to $82 \%$ preoperatively and $56 \%$ postoperatively, with much variation in previous literature [3]. The consequences

\footnotetext{
* Correspondence: oships@hallym.ac.kr

${ }^{1}$ Department of Orthopaedic Surgery, Hallym University Sacred Heart Hospital, Hallym University School of Medicine, 896 Pyeongchon-Dong, Dongan-gu, Anyang 431-070, South Korea

Full list of author information is available at the end of the article
}

of POUR can be more complicated with potential local and distant sequelae. Apart from causing unnecessary pain and discomfort to patients, bladder dysfunction can lead to urinary tract infection (UTI) or bacteremia, thereby acting as a source of infection for any implants and sepsis. POUR has been associated with the risk of bladder overdistension, which may produce permanent detrusor dysfunction and increase the post-void residual volume (PVR). Repeated attempts to catheterize the bladder can predispose patients to UTI. Nevertheless, less attention is paid to POUR compared with postoperative wound infections, bleeding, ileus, pneumonia, and delirium [4]. 
POUR is managed by intermittent or indwelling catheterization [5]. However, Scholten et al. [6] reported that most POUR patients were discharged with intermittent or indwelling catheter because the condition was not resolved at an early stage. These problems may lead to passivity, resignation, and a bedridden state [7]. One study reported that $32 \%$ of over 110,000 patients with hip fracture discharged to "skilled nursing facilities" had a urinary catheter in place, and this increased the 30-day risk for re-hospitalization for UTI and death [8]. Therefore, prevention of POUR is of paramount importance in elderly patients.

Pain is a typical stimulus to activate the sympathetic nervous system $[9,10]$. Activation of the sympathetic nervous system causes the bladder to increase its capacity and stimulates the internal urinary sphincter to remain tightly closed [11]. Likewise, most elderly patients with hip fracture have experienced voiding difficulty caused by immobility, severe pain related to fracture, and subsequent contraction of the internal sphincter of the bladder $[9,12]$. These problems may lead to perioperative delirium and POUR, which have a negative effect on the surgical outcomes [12]. Therefore, indwelling catheterization has been performed during admission for elderly patients with hip fracture in our institute to prevent POUR due to pain and immobility perioperatively.

However, there have been few studies investigating the association of the time of urinary catheter removal and POUR among elderly patients who underwent hip fracture surgery. The aim of the current study was to investigate the risk factors including the timing of indwelling catheter removal and incidence of POUR following hip fracture surgery in elderly patients.

\section{Materials and methods}

This study was conducted after obtaining ethical approval from our institutional review board (2015-I032). All available electronic medical records were retrospectively reviewed to identify patients aged $\geq 70$ years who underwent hip fracture surgery between January 2012 and January 2015. Intramedullary nailing was performed for intertrochanteric fracture, and hip arthroplasty was performed for femoral neck fracture. Patients with a history of urinary retention or urinary catheterization before admission and those who were diagnosed with benign prostatic hyperplasia (BPH), operated for that, or unable to ambulate postoperatively, were excluded in this study.

Indwelling catheterization was performed routinely for all patients just after admission. The catheter was removed considering the possibility of self-voiding when patients were able to stand and ambulate with a walker postoperatively. Patients who were unable to void $4 \mathrm{~h}$ after urinary catheter removal were identified, and the
PVR urine volume was measured using an ultrasound bladder scan or urethral catheterization to detect POUR. POUR was diagnosed if the PVR volume was $>400 \mathrm{~mL}$. Indwelling re-catheterization was performed for patients confirmed with POUR by a urologist. Those with unresolved POUR during their hospital stay were eventually discharged with an indwelling catheter. Routine followup in the urology outpatient clinic was planned 2 weeks after discharge, and oral medications were prescribed if indicated.

According to our institutional protocol, the patients were instructed to walk under tolerable weight-bearing conditions with an assistive device (walker or cane) from the second postoperative day to 4-6 weeks postoperatively. All patients received the same analgesics according to our institutional protocol for postoperative pain control: Celebrex (celecoxib; $200 \mathrm{mg}$ every $12 \mathrm{~h}$ ), Ultracet (acetaminophen; $325 \mathrm{mg} /$ tramadol $\mathrm{HCl} ; 37.5 \mathrm{mg}$ every $6 \mathrm{~h}$ ), and patient-controlled analgesia (PCA). For breakthrough pain, all patients received intravenous ketorolac (30 mg every $6 \mathrm{~h}$ as needed) in the postoperative period.

Demographic data on the age, gender, body mass index (BMI), bone mineral density (BMD), American Society of Anesthesiologists (ASA) score, and underlying diseases were obtained. As perioperative variables, the anesthesia type, operation time, amount of intraoperative infused fluids and urine output, estimated blood loss (EBL), time to rehabilitation after surgery, and type of PCA infusion were collected. In addition, the length of hospital stay, duration of PCA infusion and of indwelling catheter after surgery, and the occurrence of UTI were investigated.

The EBL was calculated according to the Gross formula as shown below.

Prediction of blood volume [13]:

Male : $604+0.0003668 \times[\text { Height }(\mathrm{cm})]^{3}+32.2 \times$ weight $(\mathrm{kg})$ Female : $183+0.000356 \times[\text { Height }(\mathrm{cm})]^{3}+33 \times$ weight $(\mathrm{kg})$

EBL calculation method [14]:

$$
\begin{aligned}
\mathrm{EBL}= & \text { blood volume } \\
& \times\left(\text { Hematocrit }_{\text {preoperative }}-\text { Hematocrit }_{\text {day } 5} \text { postoperative }\right) \\
& +\mathrm{mL} \text { of transfused red blood cell }
\end{aligned}
$$

\section{Statistical analysis}

Basic descriptive statistical analyses were used to describe the study population. Values were subjected to averaging or percentages with the use of SPSS version 17.0 (SPSS Inc., Chicago, IL, USA). Student's $t$ test was used for continuous variables and chi-square test for categorical variables between the two groups with POUR and without. A $p$ value $<0.05$ was considered as statistically significant. 
Variables with $p$ value $<0.05$ were incorporated into a forward, stepwise multivariate regression analysis to determine the risk factors for POUR. Odds ratios (OR) were obtained with $95 \%$ confidence intervals (CI) for independent risk factors. The receiver operating characteristic (ROC) curves were utilized to determine the area under the ROC curve (AUC) and cutoff value for the timing of catheter removal.

\section{Results}

During the study period, a total of 256 patients were identified. Of those, 214 patients with the mean age of 78.7 years (range, 70-99 years) were enrolled in the final cohort (Fig. 1). Of 214 patients, 162 (74.3\%) were female. Seventy-seven patients (36.0\%) had underlying diseases affecting POUR: diabetes mellitus, brain and spinal disease, or neurogenic bladder. General anesthesia was performed in 104 patients (48.6\%) and spinal anesthesia in 110 patients $(51.4 \%)$. The mean operation time was 85.0 min (range, 35-170 $\mathrm{min}$ ). The mean amount of intraoperative infused fluid was $1181.8 \mathrm{~mL}$ (range, 130-2450 $\mathrm{mL}$ ) while the mean EBL volume was $522.9 \mathrm{~mL}$ (range, $50-1200 \mathrm{~mL}$ ). The mean duration of PCA was 2.2 days (range, 1-5 days), and the indwelling catheter was left in place for an average of 3.4 days (range, $0-7$ days). The mean length of hospital stay was 24.1 days (Table 1).

Among 214 patients, POUR was observed in 68 patients (31.8\%), which is composed of 44 females (64.7\%) and 24 males. A significant difference was noted in the gender and postoperative duration of indwelling catheterization ( $p=0.016$ and $p=0.004$, respectively) between the two groups with POUR and without. More male patients developed POUR, and postoperative duration of the indwelling catheter was shorter in patients with POUR than in those without POUR (Table 2). No significant differences were observed in the age, BMI, ASA score, BMD, fracture site, underlying diseases, anesthesia type, operation time, volume of intraoperative urine output and EBL, transfusion amount, time to rehabilitation after surgery, type and duration of PCA, and duration of hospitalization between both groups.

Among 214 patients, only 11 patients (5.1\%) developed UTI, which consisted of 6 patients with POUR and 5 patients without POUR. The incidence of UTI was higher in patients with POUR $(6 / 68,8.8 \%)$ than in those without POUR (5/146, 3.4\%). However, there was no significant difference between both groups.

Multiple logistic regression analysis revealed that the indwelling period of urinary catheter (per 1-day increase, $\mathrm{OR}=0.31,95 \% \mathrm{CI} 0.14-0.78 ; p=0.016$ ) and male gender $(\mathrm{OR}=2.22$, 95\% CI 1.17-4.22; $p=0.014)$ were risk factors of POUR. ROC analysis was used to define the cutoff value for the appropriate timing of indwelling catheter removal. The AUC for the timing of catheter removal was 0.63 (95\% CI 0.56-0.70), and the cutoff value was 3.5 days after surgery (sensitivity, 51.4\%; specificity, 71.5\%) (Fig. 2).

\section{Patients aged 70 years or older undergoing hip fracture surgery $(\mathrm{N}=256)$}
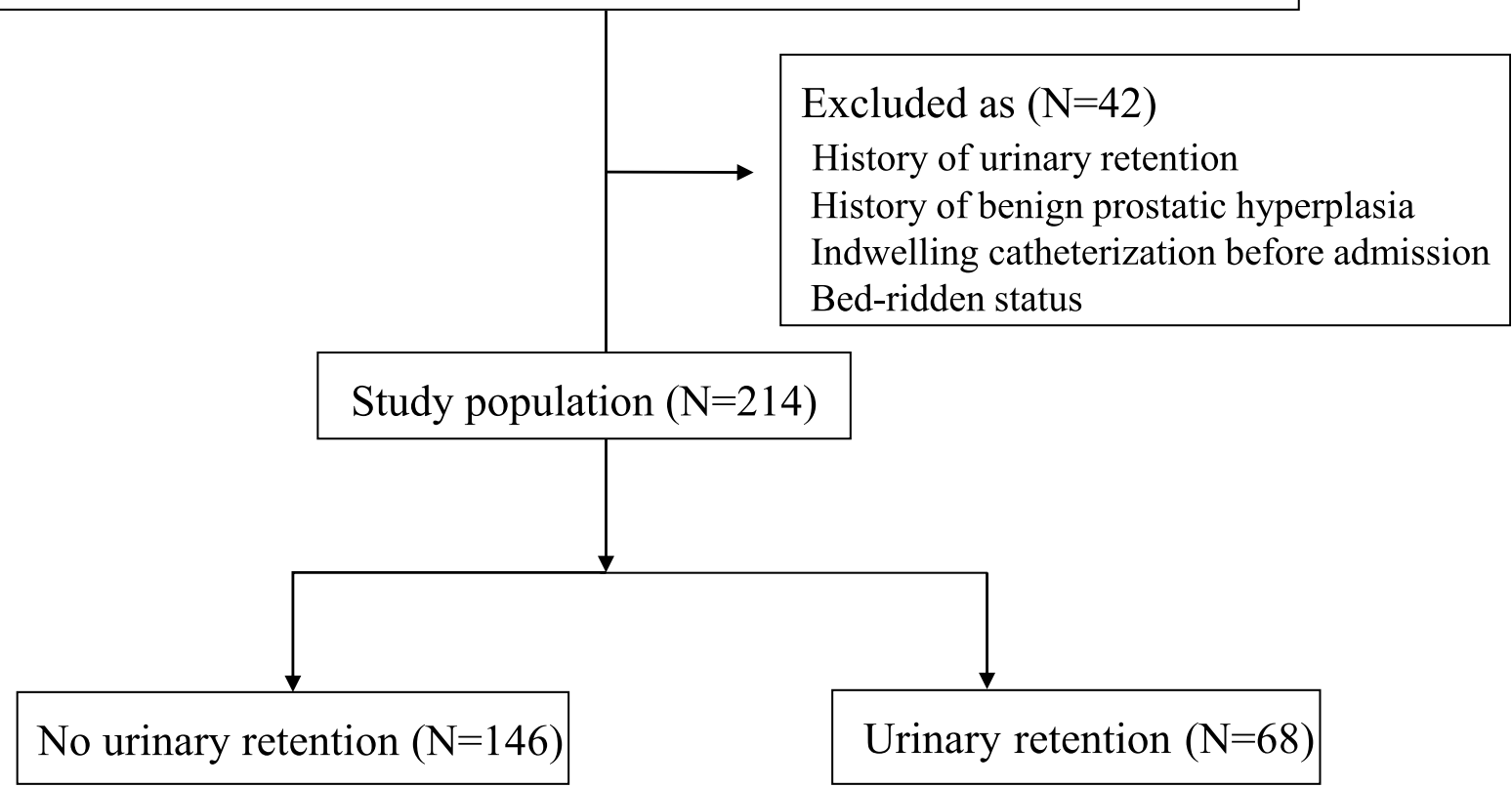

Fig. 1 Flowchart demonstrating patient selection 
Table 1 Data of 214 patients over 70 years old with hip fractures

\begin{tabular}{|c|c|}
\hline Variables & Mean (range) \\
\hline Age (years) & $78.7(70-99)$ \\
\hline Gender (men : women) & $52: 162$ \\
\hline Body mass index $\left(\mathrm{kg} / \mathrm{m}^{2}\right)$ & $22.3(13-33)$ \\
\hline Bone mineral density ( $T$-score) & $-2.6(-5.3$ to -0.3$)$ \\
\hline ASA score & $2.9(2-4)$ \\
\hline$\|$ & 37 \\
\hline III & 155 \\
\hline IV & 22 \\
\hline Number of underlying disease* & $0.7(0-2)$ \\
\hline Anesthesia (general : spinal) & 104:110 \\
\hline Operation time (minutes) & $85.0(35-170)$ \\
\hline $\begin{array}{l}\text { Amount of intraoperative fluid } \\
\text { infused }(\mathrm{mL})\end{array}$ & $1181.8(130-2450)$ \\
\hline Amount of estimated blood loss (mL) & $522.9(50-1200)$ \\
\hline \multicolumn{2}{|l|}{ Time to rehabilitation after surgery } \\
\hline POD 2 & 157 \\
\hline POD 3 & 48 \\
\hline POD 4 & 6 \\
\hline$\geq$ POD 5 & 3 \\
\hline PCA (intravenous : epidural) & $198: 16$ \\
\hline Duration of PCA infused (days) & $2.2(1-5)$ \\
\hline $\begin{array}{l}\text { Duration of Foley catheter } \\
\text { indwelling (days) }\end{array}$ & $3.4(0-7)$ \\
\hline Duration of hospitalization (days) & $24.1(9-105)$ \\
\hline
\end{tabular}

ASA American Society of Anesthesiologists, $P O D$ postoperative day, $P C A$ patient-controlled analgesia

*Underlying disease includes diabetes mellitus, brain disease, spinal disease, or neurogenic bladder

\section{Discussion}

Several reports revealed that POUR is highly prevalent especially in elderly patients with hip fracture [15-17]. Such condition is likely to lead to an increase in the length of hospital stay and morbidity rate. Recently, Golubovsky et al. reported that POUR was significantly associated with an increased risk of UTI and sepsis, increased length of hospital stay, and discharge to a skilled nursing facility [18]. It is of paramount importance to prevent POUR in these patients. Most elderly patients with hip fracture have experienced voiding difficulty perioperatively caused by immobility, severe pain related to fracture and surgery, and subsequent contraction of the internal sphincter of the bladder $[9,12]$. Therefore, perioperative indwelling catheterization may be an effective alternative to reduce bladder dysfunction and subsequent POUR in elderly patients with hip fracture $[16,19]$. Therefore, we have performed indwelling catheterization upon admission in all elderly patients undergoing hip fracture surgery. Previous studies reported
Table 2 Comparison data between the two groups

\begin{tabular}{|c|c|c|c|}
\hline & $\begin{array}{l}\text { POUR }(-) \\
(n=146)\end{array}$ & $\begin{array}{l}\text { POUR (+) } \\
(n=68)\end{array}$ & $\begin{array}{l}p \\
\text { value }\end{array}$ \\
\hline Age (years) & $78.6 \pm 6.6$ & $78.7 \pm 6.7$ & 0.898 \\
\hline Gender (male : female) & $28: 118$ & $24: 44$ & 0.016 \\
\hline Body mass index $\left(\mathrm{kg} / \mathrm{m}^{2}\right)$ & $22.2 \pm 3.0$ & $22.3 \pm 3.6$ & 0.470 \\
\hline ASA score & & & 0.117 \\
\hline$\|$ & 26 & 11 & \\
\hline III & 105 & 50 & \\
\hline IV & 15 & 7 & \\
\hline Bone mineral density ( $T$-score) & $-2.7 \pm 1.0$ & $-2.6 \pm 0.8$ & 0.563 \\
\hline Fracture site (neck : trochanter) & $54: 92$ & $25: 43$ & 1.000 \\
\hline $\begin{array}{l}\text { Patients with underlying diseases* } \\
(\%)\end{array}$ & $50(34.2)$ & $27(39.7)$ & 0.072 \\
\hline Anesthesia (general : spinal) & $70: 76$ & $34: 34$ & 0.883 \\
\hline Operation time (minutes) & $84.9 \pm 27.0$ & $85.0 \pm 32.0$ & 0.973 \\
\hline $\begin{array}{l}\text { Amount of intraoperative urine } \\
\text { output }(c c)\end{array}$ & $201.0 \pm 174.8$ & $202.3 \pm 170.7$ & 0.959 \\
\hline $\begin{array}{l}\text { Amount of estimated blood loss } \\
(\mathrm{mL})\end{array}$ & $504.8 \pm 199.6$ & $561.8 \pm 262.5$ & 0.115 \\
\hline Amount of transfusion (units) & $2.8 \pm 1.9$ & $3.2 \pm 2.0$ & 0.250 \\
\hline Time to rehabilitation after surgery & & & 0.854 \\
\hline POD 2 & 107 & 50 & \\
\hline POD 3 & 33 & 15 & \\
\hline POD 4 & 4 & 2 & \\
\hline$\geq$ POD 5 & 2 & 1 & \\
\hline PCA (intravenous : epidural) & $137: 9$ & $61: 7$ & 0.402 \\
\hline Duration of PCA infused (days) & $2.2 \pm 0.6$ & $2.2 \pm 0.7$ & 0.400 \\
\hline $\begin{array}{l}\text { Duration of Foley catheter } \\
\text { indwelling after surgery (days) }\end{array}$ & $3.7 \pm 3.3$ & $2.8 \pm 1.2$ & 0.004 \\
\hline Duration of hospitalization (days) & $13.8 \pm 5.7$ & $14.7 \pm 5.5$ & 0.657 \\
\hline Urinary tract infection (\%) & $5(3.4 \%)$ & $6(8.8 \%)$ & 0.107 \\
\hline
\end{tabular}

Values are presented as mean ( \pm standard deviation)

ASA American Society of Anesthesiologists, $P O D$ postoperative day, PCA patient-controlled analgesia

*Underlying disease include diabetes mellitus, brain disease, spinal disease, and neurogenic bladder

that the frequency of UTI among elderly patients with hip fracture was between 12 and 52\% [20-22]. Early urinary catheterization may be a risk factor of UTI. However, in this study, only $11(5.1 \%)$ of elderly patients with perioperative indwelling catheterization developed UTI and the incidence was lower than other studies not performing routine indwelling catheterization at admission in elderly patients with hip fracture. We believe that routine indwelling catheterization in elderly patients with hip fracture is safe without increased risk of UTI and subsequent complications.

Previous studies have shown a broad spectrum of the incidence of POUR (7-84\%) because of variable 


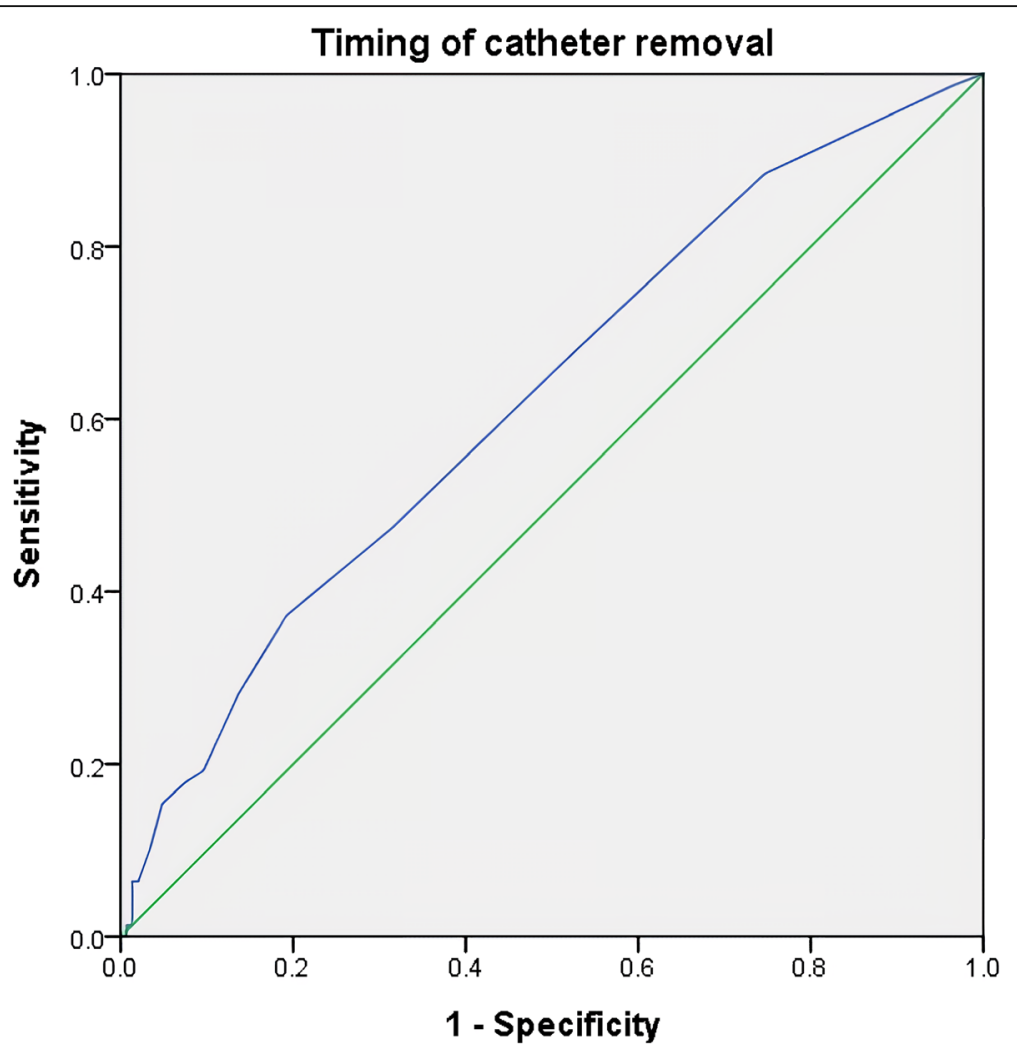

Fig. 2 Receiver operating characteristic curves for the timing of catheter removal

diagnostic criteria and risk factors $[1,23]$. In the current study, the incidence of POUR among elderly patients undergoing hip fracture surgery was $31.8 \%$. The known risk factors of POUR are age $>60$ years, spinal anesthesia, duration of surgery $>120 \mathrm{~min}$, diabetes, UTI, delirium, anticholinergic medication, analgesics, and constipation $[15,21,24]$. A number of studies have demonstrated that older patients have increased risk of POUR compared to younger patients $[18,25,26]$. However, this study included only elderly patients $\geq 70$ years undergoing hip fracture surgery. As a result, the age had no significant impact on the occurrence of POUR among elderly patients $\geq 70$ years. Several studies reported that spinal anesthesia is correlated with a high incidence of POUR $[6,27,28]$. However, spinal anesthesia had no significant impact on the occurrence of POUR in the present study because no significant difference was noted in the anesthesia type between both groups. Systemic opioid can affect the occurrence of POUR by inhibiting the release of acetylcholine from the parasympathetic sacral neurons that control detrusor contractility [17]. In our study, there was no significant difference between the two groups in terms of the type and duration of PCA infused. Therefore, opioid administration was not also associated with the occurrence of POUR. However, the overall incidence of POUR in this study might be higher than that of other studies because PCA was performed in all patients. Sex-specific diseases such as BPH may be a possible factor with a significant difference in the gender [29]. Tammela et al. [30] reported that the incidence of POUR was higher in males (4.7\%) than in females (2.9\%) out of 5220 surgical patients. A prospective cohort study that included males and females undergoing lower limb arthroplasty under spinal anesthesia reported that male sex and old age were significant risk factors of POUR [29]. In the study by Griesdale et al. [31], male gender was also identified as a significant risk factor of POUR following total joint arthroplasty. The present study was similar to the previous studies that identified male gender as a significant risk factor. The incidence of POUR in the current study was higher in male patients $(46.2 \%)$ than female patients $(27.2 \%)$. We excluded male patients who were diagnosed with or operated for $\mathrm{BPH}$ prior to the injury to rule out this risk factor. However, some patients with undiagnosed BPH might be included.

Our study showed that the indwelling period of postoperative catheterization affected the occurrence of POUR. Early removal of indwelling catheter is generally recommended to prevent catheter-related UTI and other complications [32]. However, early removal of indwelling 
catheter increased the risk of POUR following hip fracture surgery in elderly patients as shown in this study. The incidence of UTI in our study performing indwelling catheterization at admission in all patients was lower than other studies. Knight et al. [33] reported that catheterization performed 24-48 h following lower limb arthroplasty reduces POUR without increasing the risk of UTI. Meanwhile, most recent studies suggest that routine preoperative indwelling catheterization is not warranted, and intermittent catheterization is recommended to treat POUR in patients undergoing total joint arthroplasty [34, 35]. Nonetheless, these studies are limited to arthroplasty surgery while this study aimed at only elderly patients $\geq 70$ years undergoing hip fracture surgery. Patients undergoing total joint arthroplasty are relatively young compared to hip fracture patients, and postoperative ambulation and rehabilitation in arthroplasty patients can be performed earlier and more rapidly because they do not have severe pain like elderly patients those with hip fracture. Therefore, we believe that the approach to prevent and treat POUR in elderly patients with hip fracture should be different from that in arthroplasty patients, especially in terms of use of indwelling catheter and the time of catheter removal.

Our findings show that the duration of the indwelling catheter was shorter in patients with POUR than in patients without POUR. Although unnecessary indwelling catheterization should be avoided, removal of indwelling catheter should be performed considering the patient's general condition and ambulation status. Early routine removal of indwelling catheter without considering the patient's condition will more likely cause POUR and eventually increase the duration of indwelling catheterization, leading to subsequent complications and poor functional outcomes in fragile elderly patients. In most elderly patients with hip fracture, several days are needed for self-voiding after starting postoperative rehabilitation such as tilt table exercise and parallel bar walking. Postoperative rehabilitation and self-voiding may need more time after hip fracture surgery in most elderly patients with comorbidities. Riehmann et al. reported that the mean peak flow rates of voiding were lower and the PVR volume was larger in the recumbent position than the standing in elderly patients with hip fracture [36]. Therefore, early ambulation and rehabilitation were crucial to obtain satisfactory functional outcome and prevent POUR. It would be also of paramount significance that the operating surgeon identify elderly patients with increased risk of POUR to do so.

This study has several limitations. First, this was a retrospective study design. Second, there was no comparison with a control group without indwelling catheterization. Third, although the cutoff value for the timing of indwelling catheter removal was evaluated in this study, the sensitivity and specificity were relatively low.

However, this is the first study to investigate POUR in fragile elderly patients $\geq 70$ years with hip fracture. Second, we could exclude other known risk factors affecting the occurrence of POUR between the two groups. Third, we compared underlying diseases such as diabetes mellitus, brain disease, spinal disease, or neurogenic bladder that could affect the occurrence of POUR between both groups. Finally, this study provided the cutoff value for the timing of indwelling catheter removal to prevent POUR in elderly patients with hip fracture. However, prospective studies with larger cohort are needed to substantiate our results in the future.

\section{Conclusion}

The incidence of POUR in elderly patients $\geq 70$ years undergoing hip fracture surgery was $31.8 \%$. The significant risk factors were male gender and early removal of indwelling catheter after surgery. Therefore, early removal of indwelling catheter within 3 days following hip fracture surgery in elderly patients may increase the risk of POUR, especially in male patients.

\section{Abbreviations \\ ASA: American Society of Anesthesiologists; AUC: Area under the ROC curve; BMD: Bone mineral density; BMl: Body mass index; BPH: Benign prostatic hyperplasia; Cl: Confidence intervals; EBL: Estimated blood loss; OR: Odds ratios; PCA: Patient-controlled analgesia; POUR: Postoperative urinary retention; PVR: Post-void residual volume; ROC: Receiver operating characteristic; UTI: Urinary tract infection}

\section{Acknowledgements}

Not applicable

\section{Authors' contributions}

DKK contributed to the conceptualization, data analysis, and original draft preparation. CYO contributed to the conceptualization, data curation, and review. JSL contributed to the acquisition of data. HML contributed to the data analysis and review. JHY is the main surgeon and is responsible for the conceptualization, reviewing, and editing of the draft and supervision. All authors read and approved the final manuscript.

\section{Funding}

There is no funding for the current study.

Availability of data and materials

The datasets used and/or analyzed during the current study are available from the corresponding author on reasonable request.

Ethics approval and consent to participate

This study was approved by the institutional review board/Ethics Committee of Hallym University Sacred Heart Hospital (2015-1032) and was conducted in compliance with the guidelines of the Helsinki Declaration of 1975.

\section{Competing interests}

The authors declare that they have no competing interests.

\section{Author details}

${ }^{1}$ Department of Orthopaedic Surgery, Hallym University Sacred Heart Hospital, Hallym University School of Medicine, 896 Pyeongchon-Dong, Dongan-gu, Anyang 431-070, South Korea. ${ }^{2}$ Department of Urology, Hallym 
University Sacred Heart Hospital, Hallym University School of Medicine, Anyang, South Korea.

Received: 2 May 2019 Accepted: 3 September 2019

Published online: 18 September 2019

\section{References}

1. Oishi CS, Williams VJ, Hanson PB, Schneider JE, Colwell CW, Walker RH. Perioperative bladder management after primary total hip arthroplasty. J Arthroplast. 1995;10(6):732-6.

2. Baldini G, Bagry H, Aprikian A, Carli F. Postoperative urinary retention: anesthetic and perioperative considerations. Anesthesiology. 2009;110(5): 1139-57.

3. Smith NK, Albazzaz MK. A prospective study of urinary retention and risk of death after proximal femoral fracture. Age Ageing. 1996;25(2):150-4

4. Tobu S, Noguchi M, Hashikawa T, Uozumi J. Risk factors of postoperative urinary retention after hip surgery for femoral neck fracture in elderly women. Geriatr Gerontol Int. 2014:14(3):636-9.

5. Balderi T, Mistraletti G, D'Angelo E, Carli F. Incidence of postoperative urinary retention (POUR) after joint arthroplasty and management using ultrasound-guided bladder catheterization. Minerva Anestesiol. 2011; 77(11):1050-7.

6. Scholten R, Kremers K, van de Groes SAW, Somford DM, Koeter S. Incidence and risk factors of postoperative urinary retention and bladder catheterization in patients undergoing fast-track total joint arthroplasty: a prospective observational study on 371 patients. J Arthroplast. 2018;33(5): 1546-51.

7. Johansson RM, Christensson L. Urinary retention in older patients in connection with hip fracture surgery. J Clin Nurs. 2010;19(15-16):2110-6.

8. Wald $\mathrm{H}$, Epstein $\mathrm{A}$, Kramer A. Extended use of indwelling urinary catheters in postoperative hip fracture patients. Med Care. 2005:43(10):1009-17.

9. de Groat WC. A neurologic basis for the overactive bladder. Urology. 1997; 50(6A Suppl):36-52 discussion 3-6.

10. Schlereth $T$, Birklein F. The sympathetic nervous system and pain. NeuroMolecular Med. 2008;10(3):141-7.

11. Griffiths D. Neural control of micturition in humans: a working model. Nat Rev Urol. 2015;12(12):695-705.

12. Lovick TA. Central control of visceral pain and urinary tract function. Auton Neurosci. 2016:200:35-42

13. Nadler SB, Hidalgo JH, Bloch T. Prediction of blood volume in normal human adults. Surgery. 1962:51(2):224-32.

14. Mercuriali F, Inghilleri G. Proposal of an algorithm to help the choice of the best transfusion strategy. Curr Med Res Opin. 1996;13(8):465-78.

15. Adunsky A, Nenaydenko O, Koren-Morag N, Puritz L, Fleissig Y, Arad M. Perioperative urinary retention, short-term functional outcome and mortality rates of elderly hip fracture patients. Geriatr Gerontol Int. 2015;15(1):65-71.

16. Skelly JM, Guyatt GH, Kalbfleisch R, Singer J, Winter L. Management of urinary retention after surgical repair of hip fracture. CMAJ. 1992;146(7): 1185-9.

17. Cialic R, Shvedov $V$, Lerman $Y$. Risk factors for urinary retention following surgical repair of hip fracture in female patients. Geriatr Orthop Surg Rehabil. 2017:8(1):39-43.

18. Golubovsky JL, llyas H, Chen J, Tanenbaum JE, Mroz TE, Steinmetz MP. Risk factors and associated complications for postoperative urinary retention after lumbar surgery for lumbar spinal stenosis. Spine J. 2018;18(9):1533-9.

19. Wells DL, Saltmarche A. Voiding dysfunction in geriatric patients with hip fracture: prevalence rate and tentative nursing interventions. Orthop Nurs. 1986:5(6):25-8

20. Halleberg Nyman M, Johansson JE, Persson K, Gustafsson M. A prospective study of nosocomial urinary tract infection in hip fracture patients. J Clin Nurs. 2011:20(17-18):2531-9.

21. Garcia-Alvarez F, Al-Ghanem R, Garcia-Alvarez I, Lopez-Baisson A, Bernal M. Risk factors for postoperative infections in patients with hip fracture treated by means of Thompson arthroplasty. Arch Gerontol Geriatr. 2010;50(1):51-5.

22. Kamel HK. The frequency and factors linked to a urinary tract infection coding in patients undergoing hip fracture surgery. J Am Med Dir Assoc. 2005:6(5):316-20.

23. Lampe H, Sneller Z, Rijnberg W. Urination problems following total hip arthroplasty: insertion or not of an indwelling catheter? Ned Tijdschr Geneeskd. 1992;136(17):827-31.
24. Borrie MJ, Campbell K, Arcese ZA, Bray J, Hart P, Labate T, et al. Urinary retention in patients in a geriatric rehabilitation unit: prevalence, risk factors, and validity of bladder scan evaluation. Rehabil Nurs. 2001;26(5):187-91.

25. Mason SE, Scott AJ, Mayer E, Purkayastha S. Patient-related risk factors for urinary retention following ambulatory general surgery: a systematic review and meta-analysis. Am J Surg. 2016;211(6):1126-34.

26. Sung KH, Lee KM, Chung CY, Kwon SS, Lee SY, Ban YS, et al. What are the risk factors associated with urinary retention after orthopaedic surgery? Biomed Res Int. 2015:2015:613216.

27. Lau H, Lam B. Management of postoperative urinary retention: a randomized trial of in-out versus overnight catheterization. ANZ J Surg. 2004;74(8):658-61.

28. David M, Arthur E, Dhuck R, Hemmings E, Dunlop D. High rates of postoperative urinary retention following primary total hip replacement performed under combined general and spinal anaesthesia with intrathecal opiate. J Orthop. 2015;12(Suppl 2):S157-60.

29. Sarasin SM, Walton MJ, Singh HP, Clark DI. Can a urinary tract symptom score predict the development of postoperative urinary retention in patients undergoing lower limb arthroplasty under spinal anaesthesia? A prospective study. Ann R Coll Surg Engl. 2006;88(4):394-8.

30. \Tammela T, Kontturi M, Lukkarinen O. Postoperative urinary retention: I. Incidence and predisposing factors. Scand J Urol Nephrol. 1986;20(3):197-201.

31. Griesdale DE, Neufeld J, Dhillon D, Joo J, Sandhu S, Swinton F, et al. Risk factors for urinary retention after hip or knee replacement: a cohort study. Can J Anesth. 2011;58(12):1097-104.

32. Kunin CM, McCormack RC. Prevention of catheter-induced urinary-tract infections by sterile closed drainage. N Engl J Med. 1966;274(21):1155-61.

33. Knight RM, Pellegrini VD. Bladder management after total joint arthroplasty. J Arthroplast. 1996;11(8):882-8.

34. Van den Brand I, Castelein R. Total joint arthroplasty and incidence of postoperative bacteriuria with an indwelling catheter or intermittent catheterization with one-dose antibiotic prophylaxis: a prospective randomized trial. J Arthroplast. 2001:16(7):850-5.

35. Iorio R, Whang W, Healy WL, Patch DA, Najibi S, Appleby D. The utility of bladder catheterization in total hip arthroplasty. Clin Orthop Relat Res. 2005; 432:148-52

36. Riehmann M, Bayer WH, Drinka PJ, Schultz S, Krause P, Rhodes PR, et al. Position-related changes in voiding dynamics in men. Urology. 1998;52(4): $625-30$

\section{Publisher's Note}

Springer Nature remains neutral with regard to jurisdictional claims in published maps and institutional affiliations.

Ready to submit your research? Choose BMC and benefit from:

- fast, convenient online submission

- thorough peer review by experienced researchers in your field

- rapid publication on acceptance

- support for research data, including large and complex data types

- gold Open Access which fosters wider collaboration and increased citations

- maximum visibility for your research: over $100 \mathrm{M}$ website views per year

At BMC, research is always in progress.

Learn more biomedcentral.com/submissions 